\title{
Article
}

\section{TFF1 Induces Aggregation and Reduces Motility of Helicobacter pylori}

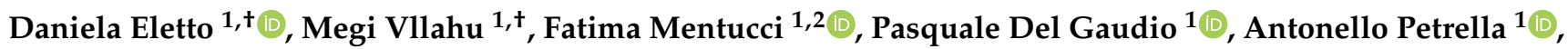 \\ Amalia Porta ${ }^{1, *(1)}$ and Alessandra Tosco $1, *$ (D) \\ 1 Department of Pharmacy, University of Salerno, 84084 Fisciano (SA), Italy; daeletto@unisa.it (D.E.); \\ mvllahu@unisa.it (M.V.); fmentucci@unisa.it (F.M.); pdelgaudio@unisa.it (P.D.G.); apetrella@unisa.it (A.P.) \\ 2 PhD Program in Drug Discovery and Development, University of Salerno, 84084 Fisciano (SA), Italy \\ * Correspondence: aporta@unisa.it (A.P.); tosco@unisa.it (A.T.); Tel.: +39-089-969455 (A.P.); \\ +39-089-969797 (A.T.) \\ + These authors equally contributed.
}

Citation: Eletto, D.; Vllahu, M.; Mentucci, F.; Del Gaudio, P.; Petrella, A.; Porta, A.; Tosco, A. TFF1 Induces Aggregation and Reduces Motility of Helicobacter pylori. Int. J. Mol. Sci. 2021, 22, 1851. https://doi.org/ $10.3390 /$ ijms 22041851

Academic Editor: Tanneke Den Blaauwen

Received: 12 January 2021

Accepted: 9 February 2021

Published: 12 February 2021

Publisher's Note: MDPI stays neutral with regard to jurisdictional claims in published maps and institutional affiliations.

Copyright: (c) 2021 by the authors. Licensee MDPI, Basel, Switzerland. This article is an open access article distributed under the terms and conditions of the Creative Commons Attribution (CC BY) license (https:// creativecommons.org/licenses/by/ $4.0 /)$.

\begin{abstract}
Gastric cancer is considered one of the most common malignancies in humans and Helicobacter pylori infection is the major environmental risk factor of gastric cancer development. Given the high spread of this bacterium whose infection is mostly asymptomatic, H. pylori colonization persists for a long time, becoming chronic and predisposing to malignant transformation. The first defensive barrier from bacterial infection is constituted by the gastric mucosa that secretes several protective factors, among which is the trefoil factor 1 (TFF1), that, as mucin 5AC, binds the bacterium. Even if the protective role of TFF1 is well-documented, the molecular mechanisms that confer a beneficial function to the interaction among TFF1 and H. pylori remain still unclear. Here we analyze the effects of this interaction on H. pylori at morphological and molecular levels by means of microscopic observation, chemiotaxis and motility assays and real-time PCR analysis. Our results show that TFF1 favors aggregation of $H$. pylori and significantly slows down the motility of the bacterium across the mucus. Such aggregates significantly reduce both $f l g E$ and flaB gene transcription compared with bacteria not incubated with TFF1. Finally, our results suggest that the interaction between TFF1 and the bacterium may explain the frequent persistence of $H$. pylori in the human host without inducing disease.
\end{abstract}

Keywords: TFF1; Helicobacter pylori; motility; aggregates

\section{Introduction}

Gastric cancer represents one of the most common and deadly neoplasms in the world [1]. The evidence reports a strong association between gastric adenocarcinoma and Helicobacter pylori infection [2,3]. This Gram-negative bacterium normally colonizes the human gastric mucosa of $50-75 \%$ of the worldwide population, representing one of the most common pathogens [4]. However, only up to $10 \%$ of infected individuals develop duodenal ulceration and ultimately gastric cancer, whereas the majority remains asymptomatic $[5,6]$. The lack of symptoms does not alarm whom $H$. pylori infects and therefore in most cases there is a tendency to underestimate the presence of the bacterium. Its persistence in the stomach leads to a state termed "chronic superficial gastritis", characterized by a profound inflammation that, along with other factors (age of infection, genetic traits, bacterial virulence and environmental factors), will then determine the outcome of the infection.

H. pylori is known to colonize specifically human gastric mucosa and particularly at the antrum and/or corpus level, depending on chemotaxis signals [7]. Its location is merely in the gastric pits and in the mucus layer rather than the epithelial cells and represents a unique feature that is receiving great attention. Indeed, the mucus plays a protective role against detrimental factors as low $\mathrm{pH}$ and pathogens act as primary immune defenses [8,9]. H. pylori co-localizes specifically with the mucin MUC5AC, secreted by normal gastric 
mucosal cells and thereby remains sequestered within the mucus layer $[10,11]$. Another factor that might participate in preventing $H$. pylori colonization is the trefoil factor 1 (TFF1).

TFF1 is one of the mucus components, known to interact with $H$. pylori and to play a protective role during infection. It is a member of the Trefoil Factor Family (the other two are TFF2 and TFF3) that is involved in mucosal protection by inducing repair and helping the formation of a stable mucus gel layer along with mucins [12,13]. It is constitutively secreted and co-expressed with the gastric mucin MUC5AC by mucus secretory cells of the gastric mucosa and is present in the stomach in three molecular forms-monomeric, homodimeric and heterodimeric (bound to a gastrokine 2 (GKN2), a IgG Fc binding protein (FCGBP) and an unknown protein/60 k) [14]. As the homodimer TFF1 binds to $H$. pylori [15] probably via its C-terminal region [16], which is also able to bind copper ions, this in turn promotes the formation of the homodimeric form [17]. H. pylori interacts with TFF1 through the lipopolysaccharides (LPS) in particular, the rough-form of LPS (RF-LPS), in a-pH dependent manner [18].

TFF1 is predominantly localized in the stomach, probably because it binds almost exclusively to gastric mucins and does not interact with colonic mucins [19]. Additionally, Helicobacter infection is characterized by host and tissue specificity, therefore their interaction was suggested to have a role in mediating the tropism of the bacterium for the stomach. Indeed, H. pylori also adheres to rat and bovine mucins, but natural infections in animals other than primates do not occur, probably because of physiological conditions, LPS composition of $H$. pylori and molecular features of TFF1 that determine such specificity of the bacterium. Given the high host specificity and tropism of $H$. pylori, it is still unclear if the interaction favors the bacterium persistence in the gastric environment or prevents the damage of the infection due to the protective functions of TFF1, or both.

Gastric biopsies from positive patients showed a reduced expression of TFF1 compared to uninfected ones, both at protein and mRNA levels [20,21]. However, these data are few and take into account only the chronic phase of infection. We recently demonstrated that TFF1 expression is differently regulated in a mouse model of Helicobacter infection. In particular, a downregulation is observed during the chronic phase, while an up-regulation of TFF1 characterizes the acute phase [22]. The over-expression of TFF1 during the acute phase is in agreement with cellular studies that report induction of TFF1 upon Helicobacter infection [23]. This observation, together with the protective effect of the gastrointestinal protein on the Helicobacter-induced damage [24,25], corroborates the beneficial role of the trefoil factor at the onset of infection.

Here we analyse, at a molecular and morphological level, the interaction between TFF1 and H. pylori in the context of mucus-secreting cells and we found a significant change in the motility of bacterium aggregates induced by TFF1.

\section{Results}

\section{1. hTFF1 Binds H. pylori but Not H. felis}

H. pylori is known to bind the homodimeric form of human TFF1 (hTFF1) and it has been suggested that the binding might contribute to the tropism of H. pylori for the stomach. Given the tissue- and species-specific H. pylori colonization, we hypothesized that the interaction of hTFF1-Helicobacter occurs preferentially with $H$. pylori. Therefore, we looked at the interaction of hTFF1 with bacteria by detecting the protein pulled down after bacteria sedimentation. We used two different Helicobacter strains (H. pylori and H. felis) and another Gram-negative bacterial strain (E. coli JM109). As a source of TFF1 protein we used supernatants from two mammalian cell lines (AGS-AC1, MCF7) and the human recombinant protein TFF1 (hrTFF1), produced and purified from the E. coli $B L R$-DE3-pLysS strain.

As reported in Figure 1A, supernatants of inducible hyper-expressing AGS-AC1 clone, containing TFF1 upon doxycycline stimulation, show a specific interaction with H. pylori. Indeed, the only signal detected by the anti-TFF1 antibody via Western blot is observed when the supernatants were incubated with $\mathrm{H}$. pylori and not with $\mathrm{H}$. felis 
or E. coli (Figure 1A). A loading control of the experiment is reported in Figure S1. To corroborate these data, H. pylori and H. felis were incubated with two more sources of TFF1-supernatants from human breast cancer MCF7 cells, known to secrete high levels of TFF1, and the hrTFF1. The recombinant protein was used at two different concentrations, 0.6 and $6 \mu \mathrm{g} / \mathrm{mL}$.

A

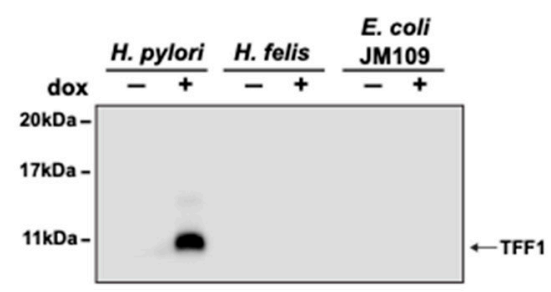

B

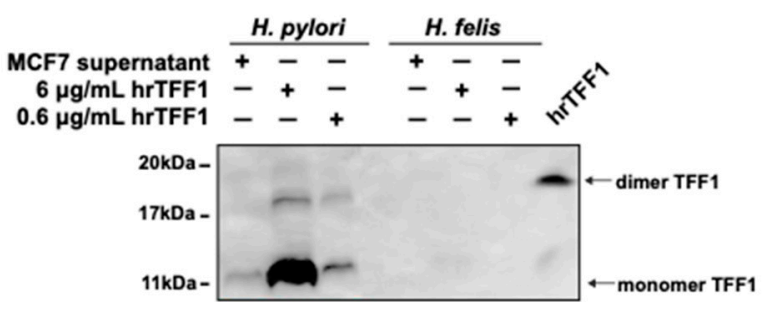

C

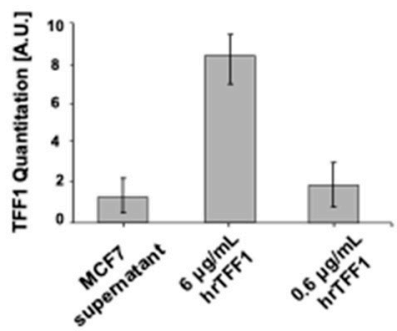

Figure 1. Trefoil factor 1 (TFF1) specifically interacts with H. pylori. Western blot analysis of pulldown experiments using (A) supernatants of AGS-AC1 clone induced or not with doxycycline, incubated with different Gram-negative bacteria; (B) TFF1 protein secreted by MCF7 cells or human recombinant protein TFF1(hrTFF1), incubated with $H$. pylori or H. felis. In the last lane hrTFF1 was loaded without reducing agents. (C) Densitometric analysis of $H$. pylori pull-down experiments in B. The experiments were repeated three independent times in technical duplicates.

These concentrations were used because $6 \mu \mathrm{g} / \mathrm{mL}$ is more or less the supposed concentration present in the gastric mucus since its motogenic activity becomes measurable starting from this concentration [26]. Moreover, the protein contained in the MCF7 supernatant was estimated to be 3-6 $\mu \mathrm{g} / \mathrm{mL}$ (Figure S2).

Our hrTFF1 protein is mainly dimeric $(\approx 90 \%)$ as shown in the last lane of the Western blot of Figure 1B where it was analyzed in non-reducing conditions in order to preserve the disulfide bonds. While the protein secreted by MCF7 is mainly monomeric $(>90 \%)$ [27]. To better compare results between recombinant protein and conditioned media we used also a ten-fold dilution, in order to realize a similar concentration of dimeric protein. As before, TFF1 was pulled down specifically by H. pylori and not by H. felis (Figure 1B). As expected, the signal intensity of MCF7 supernatants was comparable to $0.6 \mu \mathrm{g} / \mathrm{mL}$ hrTFF1 (Figure 1B), confirming that the dimeric form of the protein was pulled-down by the bacterium.

\section{2. hrTFF1 Induces H. pylori Aggregation}

As TFF1 is up-regulated during early H. pylori infection [22] and can specifically bind it, we hypothesized that the interaction might serve to protect the gastric epithelium. To better understand the role of TFF1-H. pylori interaction, $H$. pylori cultures were incubated with two different concentrations of hrTFF1 $(0.6$ and $6 \mu \mathrm{g} / \mathrm{mL})$ and the bacterial morphology was monitored over time by light microscopy. As shown in Figure 2A, H. pylori forms aggregates in a TFF1-concentration dependent manner within $4 \mathrm{~h}$. Bacteria form large clumps only if incubated with the protein, whereas at the same time of observation without hrTFF1, bacteria were still predominantly in the planktonic form. We also corroborated this result recording the formation of aggregates over time $(0,30,60,120 \mathrm{~min})$ and with 
multiple concentrations $(0,0.75,1.5,3,6 \mu \mathrm{g} / \mathrm{mL})$ of hrTFF1 (Figure S3). As expected, $H$. felis does not form hrTFF1-induced aggregates (Figure S4).

A

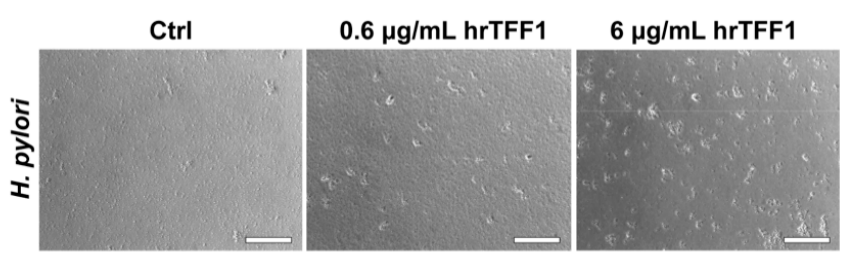

B

Ctrl
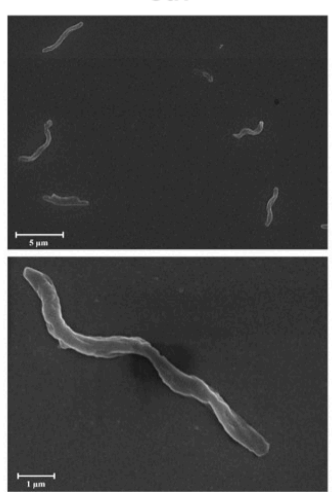

$6 \mu \mathrm{g} / \mathrm{mL}$ hrTFF1

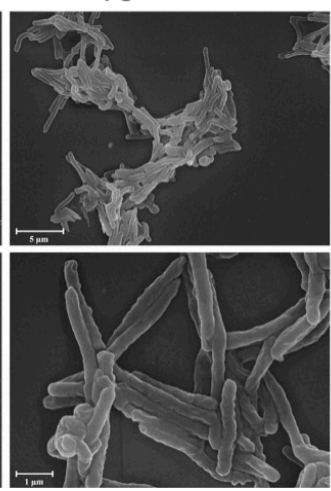

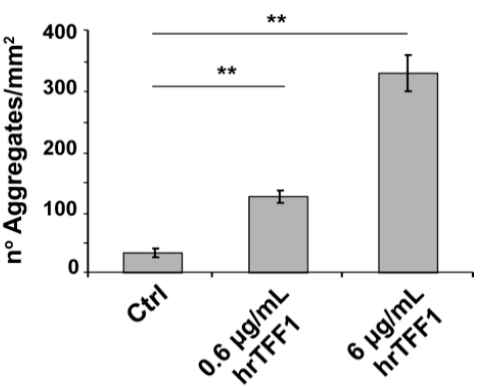

C

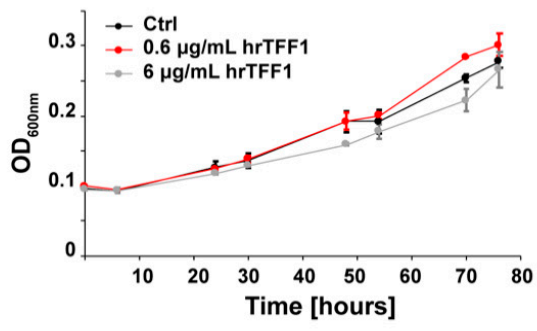

Figure 2. hrTFF1 induces formation of H. pylori aggregates. (A) Optical images of H. pylori incubated with or without 0.6 and $6 \mu \mathrm{g} / \mathrm{mL}$ of hrTFF1. Scale bar $150 \mu \mathrm{m}$. Panel on the right side reports the histograms quantification of bacterial aggregates. Data are mean of 3 independent experiments in technical duplicates $(n=6) \pm$ SD. $\left(t\right.$-test; $\left.{ }^{* *} p \leq 0.01\right)$. (B) Scanning electron microscopy (SEM) images of $H$. pylori incubated with or without $6 \mu \mathrm{g} / \mathrm{mL}$ of hrTFF1. Scale bar-5 $\mu \mathrm{m}$ (upper panels), $1 \mu \mathrm{m}$ (lower panels). (C) Growth curves of H. pylori incubated with or without 0.6 and $6 \mu \mathrm{g} / \mathrm{mL}$ of hrTFF1. Data are mean of 3 independent experiments in technical duplicates $(n=6) \pm$ SD.

Bacterial aggregates were then observed by scanning electron microscopy (SEM) to examine H. pylori morphology. Figure 2B shows that the incubation of the bacteria with TFF1 is accompanied by a morphological transformation from a spiral-shaped to filamentous form, suggesting that the protein not only forces an interaction in the bacteria but also affects their morphology.

In order to explore if TFF1-dependent aggregation could influence H. pylori proliferation, we monitored growth of bacteria incubated with or without the protein. To avoid being misleading, the bacterial aggregates were fully dispersed by pipetting prior each optical density measurement. The co-incubation with the protein did not cause a statistically significant effect on the proliferation of H. pylori as the bacteria showed the same growth rate in any of the tested conditions (Figure 2C).

\section{3. hrTFF1 Affects H. pylori Motility}

Once having assessed the formation of TFF1-induced aggregates, we hypothesized that this phenomenon could have an effect on the bacterium chemiotaxis and/or motility. To address this hypothesis, we first performed a capillary chemotaxis assay following the procedure reported by Cerda et al. [28]. The first question was whether TFF1 had chemoattractant or chemorepellent activity towards H. pylori. To this aim, the protein was loaded in the syringe and after $45 \mathrm{~min}$ of incubation all bacteria that moved from the disposable tip towards the syringe were recovered and plated on selective medium for bacterial colony counts. Figure 3A shows that TFF1 has no chemotactic effect on $H$. pylori, if compared to the buffer, while the positive control $\mathrm{HCl}$ works as a chemorepellent as expected. 
A

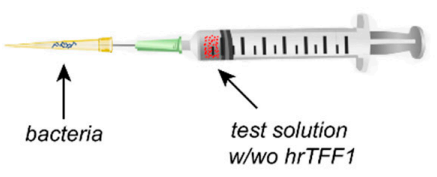

B

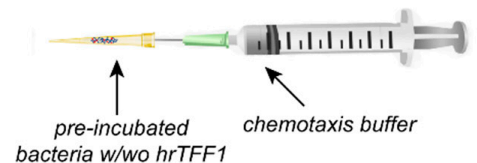

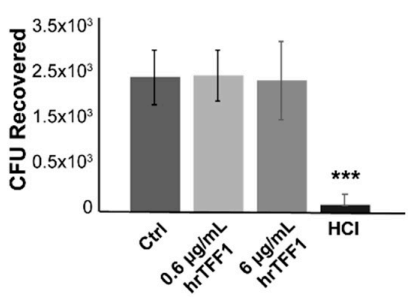

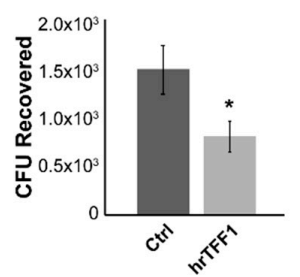

Figure 3. hrTFF1 affects H. pylori motility. (A) Left side, cartoon of the experimental procedurebacterial suspension was put in the tip, while the syringe was filled with chemotaxis solution with or without 0.6 and $6 \mu \mathrm{g} / \mathrm{mL}$ hrTFF1. Right side, bacteria that have been moved from the tip towards solutions were recovered and counted as colony forming units (CFU). (B) Left side, cartoon of the experimental procedure-pre-incubated bacteria, with or without $6 \mu \mathrm{g} / \mathrm{mL}$ hrTFF1, were put in the tip, while the syringe was filled only with the chemotaxis buffer. Right side, bacteria that have been moved towards the syringe, were counted as CFU. Data are mean of 3 independent experiments in technical duplicates $(n=6) \pm \mathrm{SD}$. $\left(t\right.$-test, $\left.{ }^{*} p \leq 0.05 ; * * * p \leq 0.001\right)$.

The second question was whether TFF1-induced aggregation could influence $H$. pylori movements. To this aim, bacteria were pre-incubated with or without $6 \mu \mathrm{g} / \mathrm{mL}$ hrTFF1 for $1.5 \mathrm{~h}$ (the minimum time necessary to induce aggregation), placed in the disposable tip and attached to the syringe needle. As shown in Figure 3B, the number of bacteria recovered from the syringe in which Helicobacter was pre-incubated with hrTFF1 was significantly reduced compared to the control conditions (bacteria without hrTFF1), suggesting that TFF1, by inducing aggregation, reduces bacterial motility towards the chemotaxis buffer.

As the TFF1-H. pylori interaction occurs within the mucus, to further investigate the influence of the TFF1 protein on $H$. pylori motility, we set up a motility assay using the mucus collected from the HT29-E12 clone. The mucus was harvested after 21 days of culturing since it has been reported to contain high levels of TFFs and mucins [29]. Subsequently, it was layered on a 24 transwell filter insert and bacteria were set down on it (Figure 4A). Mucus per se slowed down the migration since the majority of bacteria took $30 \mathrm{~min}$ to reach the lower chamber, when directly layered on the transwell filter (data not shown). Figure 4B shows that pre-incubation with hrTFF1 protein significantly reduced the number of cells recovered in the lower chamber.

A

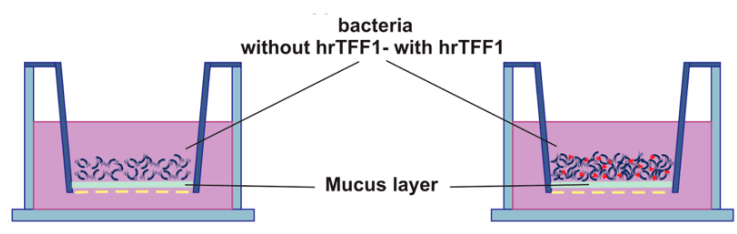

B

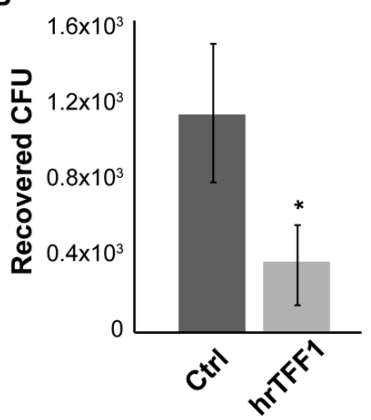

Figure 4. hrTFF1 delays motility of H. pylori across the mucus. (A) Graphical representation of the mucus motility assay. (B) Bacteria recovered from the lower chamber with or without pre-incubation with $6 \mu \mathrm{g} / \mathrm{mL}$. Data are mean of 3 independent experiments in technical duplicates $(n=6) \pm \mathrm{SD}$. $\left(t\right.$-test, $\left.{ }^{*} p \leq 0.05\right)$. 


\subsection{Transcriptional Regulation in hrTFF1-H. pylori Aggregates}

Finally, we explored the possibility that the TFF1 interaction and the subsequent aggregation could affect $H$. pylori gene expression. To this aim, we used the aforementioned HT29-E12 clone infected for $24 \mathrm{~h}$ with H. pylori. Figure 5 shows that in bacteria incubated with hrTFF1 prior to infection, transcript levels of $f l a B$ and $f l g E$, encoding components of the flagellum, were significantly reduced compared to the control. Similarly, virB11, encoding a component of the secretory apparatus complex $\operatorname{virB} / \mathrm{D}$, indispensable to translocate bacterial toxin to eukaryotic cells, was downregulated. However, the expression of other virulence genes (alpA, alpB, hopZ, ure A, vacA, cag1, cagA, cag25) did not change compared to the control (data not shown).

A

C
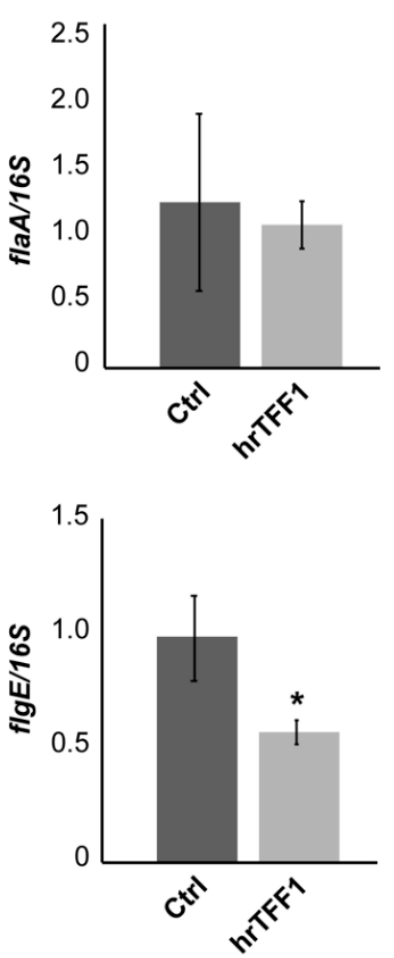

B
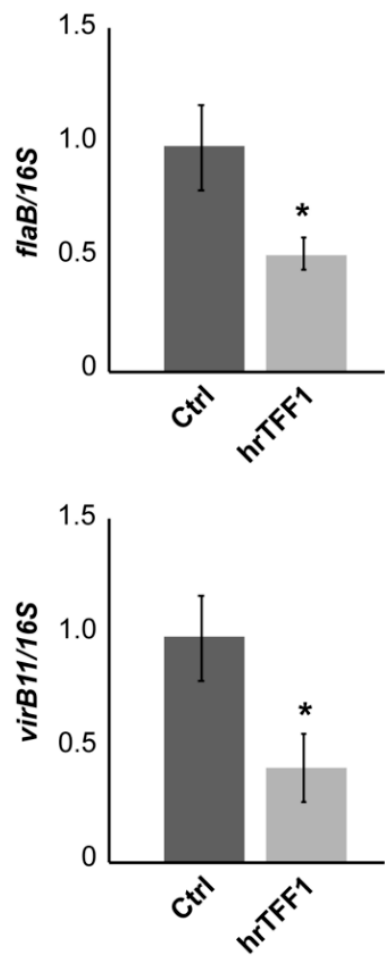

Figure 5. Real-time PCR analysis of H. pylori recovered from HT29-E12 infection. Panels (A)-(D) report expression level of $f l a A, f l a B, f l g E$ and virB11, respectively, in bacteria incubated with or without hrTFF1 prior infection. The $16 \mathrm{~S}$ was used as a house-keeping gene. Data are mean of 3 independent experiments in technical duplicates $(n=6) \pm \mathrm{SD}$. ( $t$-test, * $p \leq 0.05)$.

The reduced expression of the flagellum components is consistent with the compromised motility of $H$. pylori TFF1-dependent aggregates.

\section{Discussion}

The ability of Helicobacter pylori to bind TFF1 was previously demonstrated; different strains of $H$. pylori were found to interact with the dimeric form of the protein, while other Gram-negative bacteria did not [15]. We corroborated the existence of this interaction, also demonstrating that $H$. felis, another species of the Helicobacteraceae family, was not able to bind the TFF1 protein. This additional result is in line with the hypothesis that H. pylori co-evolved with its host for at least 100,000 years [30], and suggests that the interaction between TFF1 and H. pylori could have a role not only mediating the tropism of the bacterium within the stomach [31], but also affecting the fitness of $H$. pylori in different human hosts and explaining the frequent asymptomatic persistence.

H. pylori interacts with the dimeric form of TFF1 through its lipopolysaccharide [18]. The LPS is typically composed of three domains-the hydrophobic lipid A (or endotoxin), which anchors the molecule in the outer membrane; the core-oligosaccharide (which has 
been divided into the inner and outer core) and the variable O-antigen extending from the cell to the external environment.

The HP1191 mutant, lacking the heptosyltransferases responsible for the addition of the second LD-Hep residue of the core oligosaccharide, is no more able to bind TFF1 [29], moreover the purified Rough Form (RF) of LPS (without the O-antigen) and not the Smooth Form (SF) was able to bind the protein [18].

The core oligosaccharide region of $H$. pylori LPS has been recently redefined, suggesting that it comprises only the inner core conserved hexasaccharide of the previous model, while the O-antigen domain includes the outer core structure of the previous model [32], and according to Li et al. the conserved motif in the core oligosaccharide is essential for colonization. Considering these new findings, it seems necessary to better define the structure of the RF-LPS able to bind TFF1.

Although H. pylori and H. felis share the same sugars in the core oligosaccharide, they have different monosaccharide abundance [33]. Further investigations are required in order to better characterize the exact sugar or sequence of sugars that directly interacts with TFF1. However, our results suggest that LPS species-specific structure may be indicative of adaptive mechanisms that allow the bacteria to persist in their specific host.

To further investigate the effect of TFF1 binding on the bacterium, we first observed bacteria by light microscopy and highlighted that the formation of aggregates is incubation time- and TFF1 concentration-dependent. It has also been reported that human gastric mucins [34], and Galectin-2 [35] are able to induce aggregation, the former limiting bacterial proliferation and the latter exerting a bactericidal activity. Hence, we followed bacterial growth in the presence of TFF1, but it did not show any bactericidal activity nor inhibition of proliferation. Indeed, when we observed H. pylori morphology by means of scanning electron microscopy, we found that the bacterium does not keeps its spiral shape, but the clump formation is accompanied by a morphological transition into filamentous forms. To our knowledge, the function of elongated H. pylori cells has not been determined. However, as it has been suggested for the formation of aggregates/biofilms, this morphological transformation may play a protective role against adverse environmental factors. In particular, it has been suggested that the formation of aggregates could also be beneficial for bacteria, protecting them from antibiotics and also favoring the development of resistance, and for this reason disruption of aggregates during the eradication therapy could make it more effective [34].

Interesting, the aggregate formation was associated with the dysregulation of virB11, a virulence gene encoding a component of the secretory apparatus complex, virB/D, while, the expression of other virulence genes required for adhesion and invasion, such as alp $A$, alpB, hopZ, urea, vacA, cag1, cagA and cag25, did not change.

Furthermore, following the hypothesis that TFF1 could affect bacterial movements, we investigated the potential chemotactic effect of the protein on the bacteria but we did not observe any modification of bacterial migration towards the protein, compared to the control buffer. On the other hand, when bacteria were pre-incubated with TFF1, their migration towards the buffer was significantly impaired. To better corroborate this evidence, we set up a motility assay measuring the bacteria motility through a mucus layer, mimicking a physiological environment. Mucus represents a natural protection that strongly prevents bacterial movements. Mucus samples isolated from healthy and diseased individuals have shown differences in micro-rheological properties, as in patient with tumors the mucus appears less viscous and more permeable to bacteria that can swim faster [36]. For our purposes, we used mucus produced by the HT29-E12 clone, which is not exactly as the native one, but contains MUC5AC, TFF1 and TFF3 [29]. We found that the mucus by itself impaired bacteria movements and pre-incubation of $H$. pylori with TFF1 significantly slowed down its migration throughout the mucus.

H. pylori is a lophotrichous bacterium with 4-8 flagella. Helical shape and flagellarbased motility are used by $H$. pylori to penetrate the viscous mucus layer and colonize the stomach [37]. 
The bacterial flagellum is composed of multiple types of protein and among these FlgE is the main protein of the flagellar hook, while FlaA and FlaB are the components of the flagellar filament. Since strains lacking the $f l g E$ gene and $f l a A$ or $f l a B$ genes showed no motility or exhibited lower motility, respectively [38,39], we investigated whether TFF1 could affect their expression. As expected, in TFF1-dependent $H$. pylori aggregates, both $f l g E$ and $f l a B$ genes were significantly less transcribed compared to bacteria not incubated with TFF1, while $f l a A$ gene transcription appeared to be not affected. This is not surprising since $H$. pylori flagellar-related genes are divided in three classes and their transcription is controlled by three different RNA polymerase sigma factors- $\sigma 80$ (RpoD), $\sigma 54(\mathrm{RpoN})$ and $\sigma 28$ (FliA). In particular, the two flagellins FlaA (the major constituent) and FlaB (the minor constituent) are regulated by $\sigma 28$ and $\sigma 54$ factors, respectively. They are both necessary for full motility [39], but they can be differently regulated by environmental factors.

In conclusion, although most virulence factors were not affected, the ability of TFF1 to induce the formation of aggregates in which bacteria lose their spiral shape and exhibit reduced motility may explain the frequent persistence of $H$. pylori in the human host without inducing disease.

\section{Materials and Methods}

\subsection{Cell Cultures}

HT29-E12, a mucus secreting sub-clone of the human colorectal adenocarcinoma cell line HT29-MTX (a generous gift from Professor Per Artursson, Uppsala University, Sweden), AGS-AC1, a TFF1 inducible hyper-expressing clone previously described [40] and MCF7 (breast cancer cell line).

The aforementioned cell lines were cultured in Dulbecco's Modified Eagle Medium (DMEM, Euroclone, Austria), supplemented with 10\% $(v / v)$ fetal bovine serum (FBS, Euroclone, South America origin, EU approved), $100 \mathrm{U} / \mathrm{mL}$ penicillin and $100 \mu \mathrm{g} / \mathrm{mL}$ streptomycin (Euroclone, France). Medium for AGS-AC1 was supplemented with $600 \mu \mathrm{g} / \mathrm{mL}$ G-418 (Sigma-Aldrich, Saint Louis, MO, USA) and TFF1 expression was induced with $1 \mu \mathrm{g} / \mathrm{mL}$ of Doxycycline (Sigma-Aldrich, Saint Louis, MO, USA). All cell lines were maintained at $37{ }^{\circ} \mathrm{C}$ in a $5 \% \mathrm{CO}_{2}$ atmosphere.

\subsection{Bacterial Strains and Culture Conditions}

H. pylori P12 strain, kindly provided by Dr. Marguerite Clyne (University College Dublin), and H. felis strain ATCC 49179, were cultured on selective Columbia agar (Oxoid, Basingstoke, Hampshire, UK) containing $7 \%(v / v)$ defibrinated horse blood (Oxoid, Basingstoke, Hampshire, UK) supplemented with antibiotic mix (DENT or Skirrow, respectively, Oxoid, Basingstoke, Hampshire, UK). Bacteria plates were incubated for 3-4 days in a capnophilic atmosphere with $10 \% \mathrm{CO}_{2}$. Once grown on the plate, bacteria were scraped using brain heart infusion (BHI Oxoid, Basingstoke, Hampshire, UK) and measured at optical density at $600 \mathrm{~nm}\left(\mathrm{OD}_{600}\right)$ considering $1 \mathrm{OD}_{600}=1 \times 10^{8}$ bacteria $/ \mathrm{mL}$.

Escherichia coli strains (JM109 and DH5 $\alpha$ ) were grown in LB (10 g/L tryptone, $5 \mathrm{~g} / \mathrm{L}$ yeast extract and $5 \mathrm{~g} / \mathrm{L} \mathrm{NaCl}, \mathrm{pH}$ 7) under shaking at $37^{\circ} \mathrm{C}$.

\subsection{Human Recombinant TFF1 Production and Purification}

E. coli BLR (DE3) pLysS containing the hrTFF1-pIVEX vector, encoding the human recombinant TFF1, were inoculated in LB liquid medium supplemented with $100 \mu \mathrm{g} / \mathrm{mL}$ of Ampicillin (Amp) and incubated for $16 \mathrm{~h}$ at $37^{\circ} \mathrm{C}$ under shaking. After $24 \mathrm{~h}, 20 \mathrm{~mL}$ of bacterial culture was diluted in $1 \mathrm{~L}$ of LB liquid medium supplemented with $100 \mu \mathrm{g} / \mathrm{mL}$ of Amp and incubated at $37^{\circ} \mathrm{C}$ under shaking. When the culture reached an $\mathrm{OD}_{600}$ of $\approx 0.8$, protein expression was induced by adding $1 \mathrm{mM}$ Isopropyl $\beta$ - $\mathrm{d}$-1-thiogalactopyranoside (IPTG), and growth was allowed for 2 more hours. After IPTG-induction, bacteria were harvested by centrifugation at $4000 \mathrm{~g}$ for $20 \mathrm{~min}$ at $4{ }^{\circ} \mathrm{C}$ and washed twice with $30 \mathrm{~mL}$ of PBS. 
Briefly, bacteria were resuspended in buffer A $(20 \mathrm{mM}$ sodium phosphate buffer, $\mathrm{pH} 7.4,500 \mathrm{mM} \mathrm{NaCl}$, and $30 \mathrm{mM}$ imidazole) containing a protease inhibitor and sonicated for $40 \mathrm{~min}$ ( $1 \mathrm{~min}$ on $/ 1 \mathrm{~min}$ off, at $24 \%$ of amplitude) on ice. The lysate was clarified by centrifugation at $10000 \mathrm{~g}$ for $30 \mathrm{~min}$ at $4{ }^{\circ} \mathrm{C}$, and filtered through a $0.45 \mu \mathrm{m}$ filter (Millipore, Bedford, MA, USA) and the his-tagged hrTFF1 protein was initially purified by affinity chromatography on 1-mL HisTrap HP column (Amersham Biosciences, Uppsala, Sweden) using an AKTA Purifier chromatographic system (Amersham Biosciences, Uppsala, Sweden). The eluted fractions corresponding to the chromatographic peaks were analyzed by SDS-PAGE on $18 \%$ acrylamide gel, stained with Coomassie blue and those containing the his-tagged protein were pooled and subsequently digested with the Factor Xa (Promega, Madison, WI, USA) for $30 \mathrm{~h}$ at $25^{\circ} \mathrm{C}$ to remove the his-tag. After digestion the protein was loaded again on the His-trap HP column to definitely separate it from the cleaved tag.

\subsection{Pull-down Interaction Experiment}

Cell supernatants from MCF7 or AGS-AC1 or human recombinant TFF1 (hrTFF1) (0.6 and $6 \mu \mathrm{g} / \mathrm{mL})$ were incubated with bacteria suspension $\left(5 \times 10^{7} / \mathrm{mL}\right)$ of H. pylori, H. felis, E. coli JM109 or DH5 $\alpha$ in 6-well plate for $4 \mathrm{~h}$ at $37^{\circ} \mathrm{C}$. At the end of incubation, bacteria were collected, centrifuged at $4000 \mathrm{~g}$ for $5 \mathrm{~min}$, washed with PBS (Euroclone) and centrifuged again. The pellet was resuspended in $50 \mu \mathrm{L}$ of Laemmli buffer, sonicated and centrifuged at $10000 \mathrm{~g}$ for $10 \mathrm{~min}$ at $4{ }^{\circ} \mathrm{C}$ to remove cellular debris. Then, $5 \mu \mathrm{L}$ of each lysate was analysed by Western blot and TFF1 probed by polyclonal anti-TFF1 antibody [17]. Immunoblots were developed by chemiluminescent reaction and detected by LAS 4000 (GE Healthcare Life Sciences, Waukesha, WI, USA) digital imaging system. Immunoblot bands were quantified by ImageQuant TL software version 1.2 (GE Healthcare Life Sciences, Waukesha, WI, USA). Each experiment was repeated three independent times in technical duplicates.

\subsection{Helicobacter pylori Growth Curve}

H. pylori suspension of $1.25 \times 10^{7} / \mathrm{mL}$ was incubated with hrTFF1 $(0.6$ and $6 \mu \mathrm{g} / \mathrm{mL})$ or with an equal volume or vehicle (PBS), in a 24-well plate. At 6, 24, 30, 48, 54, 70 and $76 \mathrm{~h}$ bacterial growth was monitored by measuring optical density at $600 \mathrm{~nm}\left(\mathrm{OD}_{600}\right)$ (Multiskan spectrum, Thermo, Vantaa, Finland). The experiment was repeated three independent times in technical duplicates. The results are expressed as means \pm SD. Statistical differences between the groups were evaluated by two-way ANOVA. Statistical analyses were done using PRISM4 software (GraphPad Software, La Jolla, CA, USA). A $p<0.05$ was considered statistically significant.

\subsection{Bacterial Aggregation Observation}

H. pylori $\left(7.5 \times 10^{6} / \mathrm{mL}\right)$ was incubated with or without hrTFF1 $(0.6$ and $6 \mu \mathrm{g} / \mathrm{mL})$ for $6 \mathrm{~h}$ in a 12-well plate. The experiment was repeated three independent times in technical duplicates. At $6 \mathrm{~h}$ post-incubation, six pictures per well were taken by AME-3206 Digital inverted Microscope (AMG/EVOS, Mill Creek, WA, USA), at 20× magnification. H. pylori aggregates were quantified by ImageJ 1.49 software by using the following methodconvert to 8 -bit image, apply a moments threshold (0 to 100 boundaries), and analyze clumps with a size between 100 to infinity and a circularity between $0.10-1.00$.

\subsection{Scanning Electron Microscopy Analysis}

H. pylori was grown as described above, collected from the plate and incubated in BHI broth supplemented with $10 \% \mathrm{FBS}$, at $0.1 \mathrm{OD}_{600}$. After $24 \mathrm{~h}, 1 \times 10^{6}$ bacteria were put on coverslips pre-treated with $0.01 \%(v / v)$ poly-l-lysine (Sigma-Aldrich, Saint Louis, MO, USA) in 24-well plates and incubated with or without hrTFF1 $6 \mu \mathrm{g} / \mathrm{mL}$. After $16 \mathrm{~h}$, medium was removed and bacteria fixed by $25 \%$ glutaraldehyde $(v / v)$ for $16 \mathrm{~h}$ at room temperature. Samples were then washed and dehydrated in graded alcohol of $25 \%, 50 \%$, $75 \%, 95 \%$ for $5 \mathrm{~min}$ and three times with $100 \%$ ethanol for $10 \mathrm{~min}$. Finally, each coverslip was mounted on the SEM stage and analyzed. Samples were sputtered with gold using 
a LEICA EMSCD005 metallizator producing a deposition of a 100-200 A thick gold layer. SEM images of each sample were then acquired using a Tescan Solaris UHR microscope equipped with secondary electron and backscattered electron detectors (TESCAN, Brno, Czech Republic). Analyses were conducted at $5 \mathrm{keV}$.

\subsection{Chemotaxis Assay}

\subsubsection{Analysis of TFF1 Chemiotactic Properties}

Chemotaxis assays were carried as described by Mazumder [41] and revised by Cerda et al. [28]. Bacteria were grown as described above, collected from the plate and inoculated in BHI broth supplemented with $10 \% \mathrm{FBS}$, starting from $0.8 \mathrm{OD}_{600}$. After $24 \mathrm{~h}$, bacteria were diluted in chemotaxis buffer $(10 \mathrm{mM}$ potassium phosphate, $\mathrm{pH} 7.0 ; 3.0 \%$ polyvinylpyrrolidone) up to a concentration of $4 \times 10^{7}$ bacteria $/ \mathrm{mL}\left(0.4 \mathrm{OD}_{600}\right)$ and $100 \mu \mathrm{L}$ of bacterial suspension was drawn into a disposable $200 \mu \mathrm{L}$ pipette tip. A $100 \mu \mathrm{L}$ volume of solution to be tested $(10 \mathrm{mM} \mathrm{HCl}$, hrTFF1 $6 \mu \mathrm{g} / \mathrm{mL}$, hrTFF1 $0.6 \mu \mathrm{g} / \mathrm{mL}$ diluted in chemotaxis buffer) was drawn up into a 1-mL tuberculin syringe and a $23 \mathrm{G} \times 1 \frac{1}{4}$ stainlesssteel needle $(0.6 \times 30 \mathrm{~mm})$ was used as the chemotaxis capillary. Chemotaxis buffer alone was included as control. The needle-syringe system was positioned into the pipette tip and incubated horizontally at $37^{\circ} \mathrm{C}$ under microaerophilic conditions for $45 \mathrm{~min}$. At the end of incubation, bacteria recovered from the syringe were appropriately diluted and plated onto Columbia Blood Agar (Oxoid, Basingstoke, Hampshire, UK) plates supplemented with 10\% FBS (Euroclone) and DENT (Oxoid, Basingstoke, Hampshire, UK). Colonies were counted after $4-5$ days of incubation in capnophilic atmosphere with $10 \% \mathrm{CO}_{2}$. The experiment was repeated three independent times in technical duplicates.

\subsubsection{Analysis of TFF1 Influence on H. pylori Chemotactic Behavior}

The experiment was similar to the above described except for starting bacteria that were diluted up to a concentration of $1 \times 10^{7}$ bacteria $/ \mathrm{mL}\left(\mathrm{OD}_{600}=0.1\right)$ and preincubated for $1.5 \mathrm{~h} w / w$ hrTFF1 $(6 \mu \mathrm{g} / \mathrm{mL})$, in order to favor the formation of aggregates.

Proper dilutions of the syringe content were plated for CFU (colony forming unit) counting. The experiment was repeated three independent times in technical duplicates.

\subsection{Motility Assay}

HT29-E12, mucus-secreting cells, were used as mucus producers. Once they reached confluence, day 1 started and after 20 days of culturing, replacing the medium every two days, antibiotic-containing medium was replaced with antibiotic-free medium and the mucus was collected every 2 days, avoiding mechanical stress. Once we obtained a sufficient quantity of mucus, $100 \mu \mathrm{L}$ of slurry (1:1, mucus: BHI broth) was carefully set down on the filter of a transwell system (Falcon ${ }^{\circledR}$ 353097; pore size $8 \mu \mathrm{m}$, Merck, Millipore). The lower chamber of the transwell was filled with $500 \mu \mathrm{L}$ of BHI supplemented with $10 \%$ FBS.

Bacteria were grown as described above collected from the plate and grown in BHI liquid broth supplemented with $10 \%$ FBS, starting from $0.1 \mathrm{OD}$. After $24 \mathrm{~h}, 100 \mu \mathrm{L}$ of $1 \times 10^{6}$ bacteria $/ \mathrm{mL}\left(1 \times 10^{5}\right.$ bacteria/well $)$ was preincubated for $1.5 \mathrm{~h}$ with or without hrTFF1 $(6 \mu \mathrm{g} / \mathrm{mL})$, in order to favor the formation of aggregates and then layered on the previously prepared mucus. The system was incubated at $37^{\circ} \mathrm{C}$ under microaerophilic conditions and after $24 \mathrm{~h} 50 \mu \mathrm{L}$ of the lower chamber medium was plated for CFU counting. The experiment was repeated three independent times in technical duplicates.

\subsection{Real Time-PCR}

HT29-E12 cells were cultured for 20 days before enrolling in this experiment. A total of $24 \mathrm{~h}$ prior to infection, antibiotic-containing medium was replaced with antibiotic-free medium and cells were infected with $H$. pylori with MOI 1:30 $\left(7.5 \times 10^{8}\right.$ bacteria/well $)$ in a final volume of $500 \mu \mathrm{L}$ RPMI $+10 \%$ FBS without antibiotics. Before adding bacteria to the cells, H. pylori was pre-incubated without or with $6 \mu \mathrm{g} / \mathrm{mL}$ hTFF1 for about $2 \mathrm{~h}$. Bacterial 
RNA was extracted using TriPure Isolation Reagent (Sigma-Aldrich), reverse transcribed (500 ng) into cDNA with M-MLV Reverse Transcriptase (GeneSpin S.r.l, Milan, Italy). The Real-Time PCR was performed using the Light Cycler 480 II instrument (Roche, Basel, Switzerland). Suitable dilutions of cDNA were used for each gene in a $12 \mu \mathrm{L}$ reaction using StoS Quantitative Master Mix 2X SYBR Green (GeneSping S.r.l). Primer sequences are reported in Table S1. Results from 3 independent experiments, in technical duplicates, were analyzed using the Delta-Delta CT method with $16 \mathrm{~S}$ as reference gene.

\subsection{Statistical Analysis}

The results are expressed as means $\pm \mathrm{SD}$. Data were statistically analysed using a t-test or two-Way ANOVA, as necessary. Statistical analyses and graphing were done using PRISM4 software (GraphPad Software, La Jolla, CA, USA). A $p$ value $<0.05$ was considered statistically significant.

Supplementary Materials: Supplementary materials can be found at https://www.mdpi.com/1422 $-0067 / 22 / 4 / 1851 / s 1$.

Author Contributions: Conceptualization, A.T. and A.P. (Amalia Porta); methodology, D.E., M.V., F.M., P.D.G.; validation, D.E., F.M.; investigation, D.E., M.V., F.M., P.D.G., A.P. (Antonello Petrella); data curation, D.E., A.T., A.P. (Amalia Porta); writing-original draft preparation, D.E., M.V., F.M.; writing-review and editing, A.T., A.P. (Amalia Porta); funding acquisition, A.T., A.P. (Amalia Porta) All authors have read and agreed to the published version of the manuscript.

Funding: This research was funded by: POR CAMPANIA FESR 2014/2020 Asse 1-Obiettivo specifico 1.2 Progetto: Campania OncoTerapie CUP: B61G18000470007; PRIN 2017 “Bile acids activated receptors and liver metabolism: discovery and development of novel therapeutic targets in the treatment of steato-hepatitis (NASH)"; Cod. 2017FJZZRC_003.

Institutional Review Board Statement: Not applicable

Informed Consent Statement: Not applicable

Data Availability Statement: The data presented in this study are available on request from the corresponding author.

Conflicts of Interest: The authors declare no conflict of interest.

\section{References}

1. Bray, F.; Ferlay, J.; Soerjomataram, I.; Siegel, R.L.; Torre, L.A.; Jemal, A. Global cancer statistics 2018 GLOBOCAN estimates of incidence and mortality worldwide for 36 cancers in 185 countries. CA Cancer J. Clin. 2018, 68, 394-424. [CrossRef]

2. Peek, R.M., Jr.; Blaser, M.J. Helicobacter pylori and gastrointestinal tract adenocarcinomas. Nat. Rev. Cancer 2002, 2, 28-37. [CrossRef]

3. Graham, D.Y. Helicobacter pylori update: Gastric cancer, reliable therapy, and possible benefits. Gastroenterology 2015, 148, 719-731.e3. [CrossRef]

4. Algood, H.M.; Cover, T.L. Helicobacter pylori persistence: An overview of interactions between H. pylori and host immune defenses. Clin. Microbiol. Rev. 2006, 19, 597-613. [CrossRef]

5. Wang, F.; Meng, W.; Wang, B.; Qiao, L. Helicobacter pylori-induced gastric inflammation and gastric cancer. Cancer Lett. 2014, 345, 196-202. [CrossRef] [PubMed]

6. Mentis, A.A.; Boziki, M.; Grigoriadis, N.; Papavassiliou, A.G. Helicobacter pylori infection and gastric cancer biology: Tempering a double-edged sword. Cell. Mol. Life Sci. CMLS 2019, 76, 2477-2486. [CrossRef]

7. Rolig, A.S.; Shanks, J.; Carter, J.E.; Ottemann, K.M. Helicobacter pylori requires TlpD-driven chemotaxis to proliferate in the antrum. Infect. Immun. 2012, 80, 3713-3720. [CrossRef]

8. Johansson, M.E.; Sjovall, H.; Hansson, G.C. The gastrointestinal mucus system in health and disease. Nat. Rev. Gastroenterol. Hepatol. 2013, 10, 352-361. [CrossRef]

9. Boccellato, F.; Woelffling, S.; Aki, I.M.; Sanchez, G.; Goosmann, C.; Schmid, M.; Berger, H.; Morey, P.; Denecke, C.; Ordemann, J.; et al. Polarised epithelial monolayers of the gastric mucosa reveal insights into mucosal homeostasis and defence against infection. Gut 2018, 68, 400-413. [CrossRef] [PubMed]

10. Van den Brink, G.R.; Tytgat, K.M.; Van der Hulst, R.W.; Van der Loos, C.M.; Einerhand, A.W.; Buller, H.A.; Dekker, J.H. pylori colocalises with MUC5AC in the human stomach. Gut 2000, 46, 601-607. [CrossRef] [PubMed]

11. Van de Bovenkamp, J.H.; Mahdavi, J.; Korteland-Van Male, A.M.; Buller, H.A.; Einerhand, A.W.; Boren, T.; Dekker, J. The muc5ac glycoprotein is the primary receptor for Helicobacter pylori in the human stomach. Helicobacter 2003, 8, 521-532. [CrossRef] 
12. May, F.E.; Westley, B.R. Trefoil proteins: Their role in normal and malignant cells. J. Pathol. 1997, 183, 4-7. [CrossRef]

13. Thim, L.; Madsen, F.; Poulsen, S.S. Effect of trefoil factors on the viscoelastic properties of mucus gels. Eur. J. Clin. Investig. 2002, 32, 519-527. [CrossRef]

14. Heuer, J.; Heuer, F.; Stürmer, R.; Harder, S.; Schlüter, H.; Braga Emidio, N.; Muttenthaler, M.; Jechorek, D.; Meyer, F.; Hoffmann, W. The Tumor Suppressor TFF1 Occurs in Different Forms and Interacts with Multiple Partners in the Human Gastric Mucus Barrier: Indications for Diverse Protective Functions. Int. J. Mol. Sci. 2020, 21, 2508. [CrossRef] [PubMed]

15. Clyne, M.; Dillon, P.; Daly, S.; O'Kennedy, R.; May, F.E.; Westley, B.R.; Drumm, B. Helicobacter pylori interacts with the human single-domain trefoil protein TFF1. Proc. Natl. Acad. Sci. USA 2004, 101, 7409-7414. [CrossRef]

16. Montefusco, S.; Esposito, R.; D’Andrea, L.; Monti, M.C.; Dunne, C.; Dolan, B.; Tosco, A.; Marzullo, L.; Clyne, M. Copper promotes TFF1-mediated Helicobacter pylori colonization. PLoS ONE 2013, 8, e79455. [CrossRef]

17. Tosco, A.; Monti, M.C.; Fontanella, B.; Montefusco, S.; D’Andrea, L.; Ziaco, B.; Baldantoni, D.; Rio, M.C.; Marzullo, L. Copper binds the carboxy-terminus of trefoil protein 1 (TFF1), favoring its homodimerization and motogenic activity. Cell. Mol. Life Sci. 2010, 67, 1943-1955. [CrossRef] [PubMed]

18. Reeves, E.P.; Ali, T.; Leonard, P.; Hearty, S.; O'Kennedy, R.; May, F.E.; Westley, B.R.; Josenhans, C.; Rust, M.; Suerbaum, S.; et al. Helicobacter pylori lipopolysaccharide interacts with TFF1 in a pH-dependent manner. Gastroenterology 2008, 135, 2043-2054. [CrossRef]

19. Dunne, C.; Naughton, J.; Duggan, G.; Loughrey, C.; Kilcoyne, M.; Joshi, L.; Carrington, S.; Earley, H.; Backert, S.; Robbe Masselot, C.; et al. Binding of Helicobacter pylori to Human Gastric Mucins Correlates with Binding of TFF1. Microorganisms 2018, 6, 44. [CrossRef] [PubMed]

20. Tomita, H.; Takaishi, S.; Menheniott, T.R.; Yang, X.; Shibata, W.; Jin, G.; Betz, K.S.; Kawakami, K.; Minamoto, T.; Tomasetto, C.; et al. Inhibition of gastric carcinogenesis by the hormone gastrin is mediated by suppression of TFF1 epigenetic silencing. Gastroenterology 2011, 140, 879-891. [CrossRef]

21. Van De Bovenkamp, J.H.; Korteland-Van Male, A.M.; Büller, H.A.; Einerhand, A.W.; Dekker, J. Infection with Helicobacter pylori affects all major secretory cell populations in the human antrum. Dig. Dis. Sci. 2005, 50, 1078-1086. [CrossRef] [PubMed]

22. Esposito, R.; Morello, S.; Vllahu, M.; Eletto, D.; Porta, A.; Tosco, A. Gastric TFF1 Expression from Acute to Chronic Helicobacter infection. Front. Cell. Infect. Microbiol. 2017, 7-434. [CrossRef]

23. Matsuda, K.; Yamauchi, K.; Matsumoto, T.; Sano, K.; Yamaoka, Y.; Ota, H. Quantitative analysis of the effect of Helicobacter pylori on the expressions of SOX2, CDX2, MUC2, MUC5AC, MUC6, TFF1, TFF2, and TFF3 mRNAs in human gastric carcinoma cells. Scand. J. Gastroenterol. 2008, 43, 25-33. [CrossRef]

24. Soutto, M.; Chen, Z.; Katsha, A.M.; Romero-Gallo, J.; Krishna, U.S.; Piazuelo, M.B.; Washington, M.K.; Peek, R.M., Jr.; Belkhiri, A.; El-Rifai, W.M. Trefoil factor 1 expression suppresses Helicobacter pylori-induced inflammation in gastric carcinogenesis. Cancer 2015, 121, 4348-4358. [CrossRef] [PubMed]

25. Soutto, M.; Romero-Gallo, J.; Krishna, U.; Piazuelo, M.B.; Washington, M.K.; Belkhiri, A.; Peek, R.M., Jr.; El-Rifai, W. Loss of TFF1 promotes Helicobacter pylori-induced b-catenin activation and gastric tumorigenesis. Oncotarget 2015, 6, 17911-17922. [CrossRef] [PubMed]

26. Marchbank, T.; Westley, B.R.; May, F.E.; Calnan, D.P.; Playford, R.J. Dimerization of human pS2 (TFF1) plays a key role in its protective/healing effects. J. Pathol. 1998, 185, 153-158. [CrossRef]

27. Tosco, A.; Monti, M.C.; Fontanella, B.; Rio, M.C.; Gomez-Paloma, L.; Leone, A.; Marzullo, L. Copper-binding activity of Trefoil factor 1 (TFF1): A new perspective in the study of the multifunctional roles of TFFs. Peptides 2007, 28, 1461-1469. [CrossRef]

28. Cerda, O.A.; Núñez-Villena, F.; Soto, S.E.; Ugalde, J.M.; López-Solís, R.; Toledo, H. tlpA gene expression is required for arginine and bicarbonate chemotaxis in Helicobacter pylori. Biol. Res. 2011, 44, 277-282. [CrossRef]

29. Dolan, B.; Naughton, J.; Tegtmeyer, N.; May, F.E.; Clyne, M. The interaction of Helicobacter pylori with the adherent mucus gel layer secreted by polarized HT29-MTX-E12 cells. PLOS ONE 2012, 7, e47300. [CrossRef]

30. Moodley, Y.; Linz, B.; Bond, R.P.; Nieuwoudt, M.; Soodyall, H.; Schlebusch, C.M.; Bernhöft, S.; Hale, J.; Suerbaum, S.; Mugisha, L.; et al. Age of the association between Helicobacter pylori and man. PLoS Pathog. 2012, 8, e1002693. [CrossRef]

31. Clyne, M.; May, F.E.B. The Interaction of Helicobacter pylori with TFF1 and Its Role in Mediating the Tropism of the Bacteria within the Stomach. Int. J. Mol. Sci. 2019, 20, 4400. [CrossRef]

32. Li, H.; Yang, T.; Liao, T.; Debowski, A.W.; Nilsson, H.-O.; Fulurija, A.; Haslam, S.M.; Mulloy, B.; Dell, A.; Stubbs, K.A.; et al. The redefinition of Helicobacter pylori lipopolysaccharide O-antigen and core- oligosaccharide domains. PLoS Pathog. 2017, 13, e1006280. [CrossRef] [PubMed]

33. Hynes, S.; Ferris, J.A.; Szponar, B.; Wadström, T.; Fox, J.G.; O’Rourke, J.; Larsson, L.; Yaquian, E.; Ljungh, A.; Clyne, M.; et al. Comparative chemical and biological characterization of the lipopolysaccharides of gastric and enterohepatic helicobacters. Helicobacter 2004, 9, 313-323. [CrossRef]

34. Skoog, E.; Padra, M.; Åberg, A.; Gideonsson, P.; Obi, I.; Quintana-Hayashi, M.P.; Arnqvist, A.; Lindén, S.K. BabA dependent binding of Helicobacter pylori to human gastric mucins cause aggregation that inhibits proliferation and is regulated via ArsS. Sci. Rep. 2017, 7, 40656. [CrossRef] [PubMed]

35. Sasaki, T.; Saito, R.; Oyama, M.; Takeuchi, T.; Tanaka, T.; Natsume, H.; Tamura, M.; Arata, Y.; Hatanaka, T. Galectin-2 Has Bactericidal Effects against Helicobacter pylori in a $\beta$-galactoside-Dependent Manner. Int. J. Mol. Sci. 2020, 21, 2697. [CrossRef] [PubMed] 
36. Su, C.; Padra, M.; Constantino, M.A.; Sharba, S.; Thorell, A.; Lindén, S.K.; Bansil, R. Influence of the viscosity of healthy and diseased human mucins on the motility of Helicobacter pylori. Sci Rep. 2018, 8, 9710. [CrossRef]

37. Ottemann, K.M.; Lowenthal, A.C. Helicobacter pylori uses motility for initial colonization and to attain robust infection. Infect Immun. 2002, 70, 1984-1990. [CrossRef]

38. O'Toole, P.W.; Kostrzynska, M.; Trust, T.J. Non-motile mutants of Helicobacter pylori and Helicobacter mustelae defective in flagellar hook production. Mol. Microbiol. 1994, 14, 691-703. [CrossRef] [PubMed]

39. Josenhans, C.; Labigne, A.; Suerbaum, S. Comparative ultrastructural and functional studies of Helicobacter pylori and Helicobacter mustelae flagellin mutants: Both flagellin subunits, FlaA and FlaB, are necessary for full motility in Helicobacter species. J. Bacteriol. 1995, 177, 3010-3020. [CrossRef]

40. Romano, E.; Vllahu, M.; Bizzarro, V.; Belvedere, R.; Esposito, R.; Petrella, A.; Tosco, A. TFF1 Promotes EMT-Like Changes through an Auto-Induction Mechanism. Int. J. Mol. Sci. 2018, 19, 2018. [CrossRef] [PubMed]

41. Mazumder, R.; Phelps, T.J.; Krieg, N.R.; Benoit, R.E. Determining chemotactic responses by two subsurface microaerophiles using a simplified capillary assay method. J. Microbiol. Methods 1999, 37, 255-263. [CrossRef] 